\title{
Genotypic characterization and antimicrobial resistance profile of Salmonella isolated from chicken, pork and the environment at abattoirs and supermarkets in Chongqing, China
}

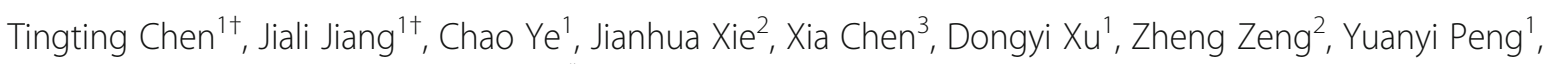
Dong-Liang $\mathrm{Hu}^{1,4}$ and Rendong Fang ${ }^{*}$

\begin{abstract}
Background: Salmonella is one of the most important foodborne pathogens, causing outbreaks of human salmonellosis worldwide. Owing to large scales of consumption markets, pork and poultry that contaminated by Salmonella could pose a tremendous threat to public health. The aim of this study was to investigate the contamination of Salmonella from chicken, pork and the environment in slaughtering and retail processes in Chongqing, China.

Results: A total of 115 Salmonella isolates were recovered from 1112 samples collected from pork, chicken and the environment. Compared with the isolation rate of samples from chicken (9.50\%) and the environment (6.23\%), samples from pork had a significant higher isolation rate (44.00\%). The isolation rates in slaughterhouses (10.76\%) and in supermarkets (10.07\%) showed no statistical difference. Thirty different serotypes were identified among all the isolates. S. Derby $(n=26)$, S. London $(n=16)$ and S. Rissen $(n=12)$ were the dominant serotypes. Antimicrobial susceptibility testing revealed that $73.04 \%$ isolates were resistant to tetracycline, followed by $66.96 \%$ to ampicillin and $59.13 \%$ to doxycycline. More than half (50.43\%) of the isolates were multidrug resistant (MDR), and most of the MDR isolates were from supermarkets. Multilocus sequence typing results showed 24 out of 115 isolates were ST40, which was the most prevalent. Furthermore, isolates from supermarkets had 20 different sequence types while isolates from slaughterhouses only had 8 different sequence types.

Conclusion: Our study highlighted that Salmonella was more frequently isolated in pork production chain than that in chicken. Compared with isolates from slaughterhouses, isolates from supermarkets had more MDR profiles and represented a wider range of serotypes and sequence types, indicating that the retail process had more diverse sources of Salmonella contamination than that of slaughtering process.
\end{abstract}

Keywords: Salmonella, Serotype, Multilocus sequence typing, Antimicrobial resistance, Slaughterhouse, Supermarket

\footnotetext{
* Correspondence: rdfang@swu.edu.cn

†Tingting Chen and Jiali Jiang contributed equally to this work.

${ }^{1}$ College of Animal Science and Technology, Southwest University, No. 2

Tiansheng Road, Beibei District, Chongqing 400715, China

Full list of author information is available at the end of the article
}

(c) The Author(s). 2019 Open Access This article is distributed under the terms of the Creative Commons Attribution 4.0 International License (http://creativecommons.org/licenses/by/4.0/), which permits unrestricted use, distribution, and reproduction in any medium, provided you give appropriate credit to the original author(s) and the source, provide a link to the Creative Commons license, and indicate if changes were made. The Creative Commons Public Domain Dedication waiver (http://creativecommons.org/publicdomain/zero/1.0/) applies to the data made available in this article, unless otherwise stated. 


\section{Background}

Salmonella, a foodborne pathogen, causes diarrhoeal diseases even death in both humans and animals [1]; it can survive in a dry environment for several weeks or even in water for several months [2]. According to previous surveys, the aetiological agent of salmonellosis largely attributed to contaminated food, which mostly were poultry and pork [3, 4]. In China, pork is the mainstream of meat consumption. Meanwhile, the consumption of poultry is rising year by year. Contamination by Salmonella in slaughtering and retail processes of chicken and pork could be a potential pathway to threat public health.

Antibiotics are widely used to improve human and animal health, and also are commonly incorporated into animal feed to improve growth rate and feed efficiency in many countries $[5,6]$ A previous report showed that China approximately consumed more than 162,000 tons of antibiotics annually, and husbandry industry account for $52.00 \%$ of the total consumption. Within the husbandry industry consumed antibiotics, $52.20 \%$ antibiotics were in pork production and $19.60 \%$ were in chicken production. As for the categories of antibiotic, sulfonamides, tetracyclines, fluoroquinolones, macrolides, $\beta$-lactams, and other antibiotics shared $5.00,7.00,17.00,26.00,21.00$, and $24.00 \%$ of the total usage [7]. Long-term exposed to antibiotics has led selection pressure to environmental bacterium, which causes antimicrobial resistance and even multidrug resistance (MDR). Antimicrobial resistance in Salmonella is a global issue. Large amount of Salmonellae resistant to extendedspectrum- $\beta$-lactams (ESBLs) and fluoroquinolones, which are important in treating salmonellosis [8]. Drug-resistant Salmonella, especially multidrug-resistant Salmonella, has been a menace to food safety and human health.

Typing methods used to investigate the characterization of Salmonella can help to enrich our knowledge of its regularity of dissemination. Serotyping presents a well-established methodology for typing of Salmonella [9]. To date, approximately 2600 serotypes have been discovered. The traditional method for serotyping, the Kauffmann-White-Le Minor Scheme requires a series of antisera, consuming time and money. Hence, a variety of typing methods were established to study the molecular epidemiologic characterization of Salmonella with its transmission dynamics, including pulsed-field gel electrophoresis (PFGE), restriction fragment length polymorphism (RFLP), amplified fragment length polymorphism (AFLP), whole-genome sequencing (WGS), and multilocus sequence typing (MLST) [10-13]. Compared with other methods, MLST is a highly repeatable typing method that based on sequence analysis of selected housekeeping genes. Recently, approximately 224,516 Salmonella strains has been uploaded by users in the MLST database [14], which becomes a convenient tool for researchers.
Contamination and antimicrobial resistance of Salmonella isolated from food-producing animals is severe worldwide [15], particularly in China [16-18]. Furthermore, several studies reported that Salmonella isolates could be recovered from farms, slaughterhouses and retail markets $[19,20]$ and a previous study indicated that Salmonella isolates could transmitted from slaughterhouses to retail markets in pig production chain [17]. However, few studies focused on the comparison of Salmonella contamination inpork and chicken as well as their slaughtering and retail chains. Therefore, the intention of this study was to compare the antimicrobial resistance, and genetic relationship of Salmonella isolates recovered from the environment, chicken and pork at abattoirs and supermarkets located in Chongqing, China.

\section{Results}

Isolation and serotyping of Salmonella from samples

A total of 115 Salmonella isolates were recovered from 1112 samples collected from slaughterhouses and supermarkets, the isolation rates form pork, chicken and the environment were 44.00, 9.50 and $6.23 \%$, respectively. Samples from pork had significant higher isolation rates than that from chicken and the environment in both slaughterhouses and supermarkets (Table 1). Within the different sources of environmental samples, Salmonellae were isolated only from floor, knives and tables at slaughterhouses, but isolated from all the sources of environmental samples at supermarkets, especially chopping boards and ice (Table 2). These results indicated that the environment in supermarkets had more diverse contamination sources than that in slaughterhouses.

Thirty serotypes in 108 isolates were successfully identified, except that seven isolates were failed in serotyping. Salmonella Derby $(n=26)$, London $(n=16)$, and Rissen $(n=12)$ were the most commonly observed serotypes in this study. Isolates from slaughterhouses had 10 serotypes (Fig. 1a) and supermarkets had 25 serotypes (Fig. 1b). Five serotypes (Derby, Typhimurium, London, Rissen, and Jerusalem) were shared both at supermarkets and slaughterhouses. Five serotypes were only detected at slaughterhouses, while 20 serotypes were only detected at supermarkets. Taken together, isolates from supermarkets showed more diverse serotypes than that from slaughterhouses.

\section{Antimicrobial susceptibility testing}

Antimicrobial susceptibility testing of 115 Salmonella isolates to 13 antimicrobials was performed. Overall, $85.22 \%(98 / 115)$ isolates were resistant to at least one antibiotic and 50.43\% (58/115) were MDR. For samples from both slaughterhouses and supermarkets, isolates showed resistance to tetracycline $(73.04 \%, 84 / 115)$ was the highest, followed by $66.96 \%(77 / 115)$ to ampicillin and $59.13 \%(68 / 115)$ to doxycycline (Fig. 2a). The rates 
Table 1 Positive isolation rates of Salmonella from different sampling sources

\begin{tabular}{|c|c|c|c|c|}
\hline Sampling Site & Sampling Source & No. of Samples & Positive No. of Isolates & Isolation Rate \\
\hline \multirow[t]{4}{*}{ Slaughterhouse and supermarket } & Chicken & 242 & 23 & $9.50 \%$ \\
\hline & Pork & 100 & 44 & $44.00 \%$ \\
\hline & Environment & 770 & 48 & $6.23 \%$ \\
\hline & Total & 1112 & 115 & $10.34 \%$ \\
\hline \multirow[t]{4}{*}{ Slaughterhouse } & Chicken & 150 & 14 & $9.33 \%$ \\
\hline & Pork & 42 & 18 & $42.86 \%$ \\
\hline & Environment & 245 & 15 & $6.12 \%$ \\
\hline & Total & 437 & 47 & $10.76 \%$ \\
\hline \multirow[t]{4}{*}{ Supermarket } & Chicken & 92 & 9 & $9.78 \%$ \\
\hline & Pork & 58 & 26 & $44.83 \%$ \\
\hline & Environment & 525 & 33 & $6.29 \%$ \\
\hline & Total & 675 & 68 & $10.07 \%$ \\
\hline
\end{tabular}

of strains that were sensitive or resistant to one or two classes of antibiotics were displayed in Fig. $2 \mathrm{~b}-\mathrm{d}$. The MDR strains (Fig. 2e) were made up of $25.86 \%(15 / 58)$ at slaughterhouses and $74.14 \%(43 / 58)$ at supermarkets.

\section{Multilocus sequence typing}

Multilocus sequence typing was used to identify the relatedness of Salmonella in pork, chicken and the environment from slaughterhouses and supermarkets. Twenty-three different sequence types (STs) were identified among 108 isolates, while 7 isolates with failed serotyping results also defected in MLST were excluded for further analysis (Fig. 3). All sequence types consist of 15 from supermarkets, 3 (ST543, ST365 and ST516) from slaughterhouses and 5 (ST19, ST34, ST40, ST155 and ST469) from both sites. Most of the sequence types were detected in less than 10 isolates, except for ST40, ST155 and ST469. The largest population of isolates were ST40 $(n=24)$, followed by ST155 $(n=19)$ and ST469 $(n=17)$. Some Salmonella isolates presented similar sequence types that belonged to the same serovar. For example, all ST40 isolates were $S$. Derby, all $S$. Rissen isolates belonged to a single cluster (ST469) and 15 out of $16 S$. London isolates were ST155. As for the relationship between MLST and antibiotic resistance, we found that ST17 and ST155 were resistant to a wide range of

Table 2 Contamination frequency of environmental samples from supermarkets and slaughterhouses

\begin{tabular}{lllll}
\hline Sampling site & Source & No. of Samples & Positive No. of Isolates & Positive Rate \\
\hline Slaughterhouse & Wash water & 30 & 0 & 0 \\
& Knives & 30 & 3 & $10.00 \%$ \\
& Floor & 30 & 10 & $33.33 \%$ \\
& Feces & 15 & 0 & 0 \\
& Apparatus & 30 & 0 & 0 \\
& Containers & 30 & 0 & 0 \\
& Tables & 30 & 2 & $6.67 \%$ \\
& Carcasses & 30 & 0 & 0 \\
Supermarket & 20 & 0 & 0 \\
& Blood & 245 & 15 & $6.12 \%$ \\
& Total & 75 & 7 & $9.33 \%$ \\
& Chopping boards & 75 & 6 & $8.00 \%$ \\
& Ice & 75 & 6 & $5.33 \%$ \\
& Knives & 75 & 4 & $8.00 \%$ \\
& Floor & 75 & 3 & $5.33 \%$ \\
& Containers & 75 & 3 & $4.00 \%$ \\
& Wash water & 75 & 33 & $4.00 \%$ \\
& Tables & 525 & $6.29 \%$ \\
\hline
\end{tabular}




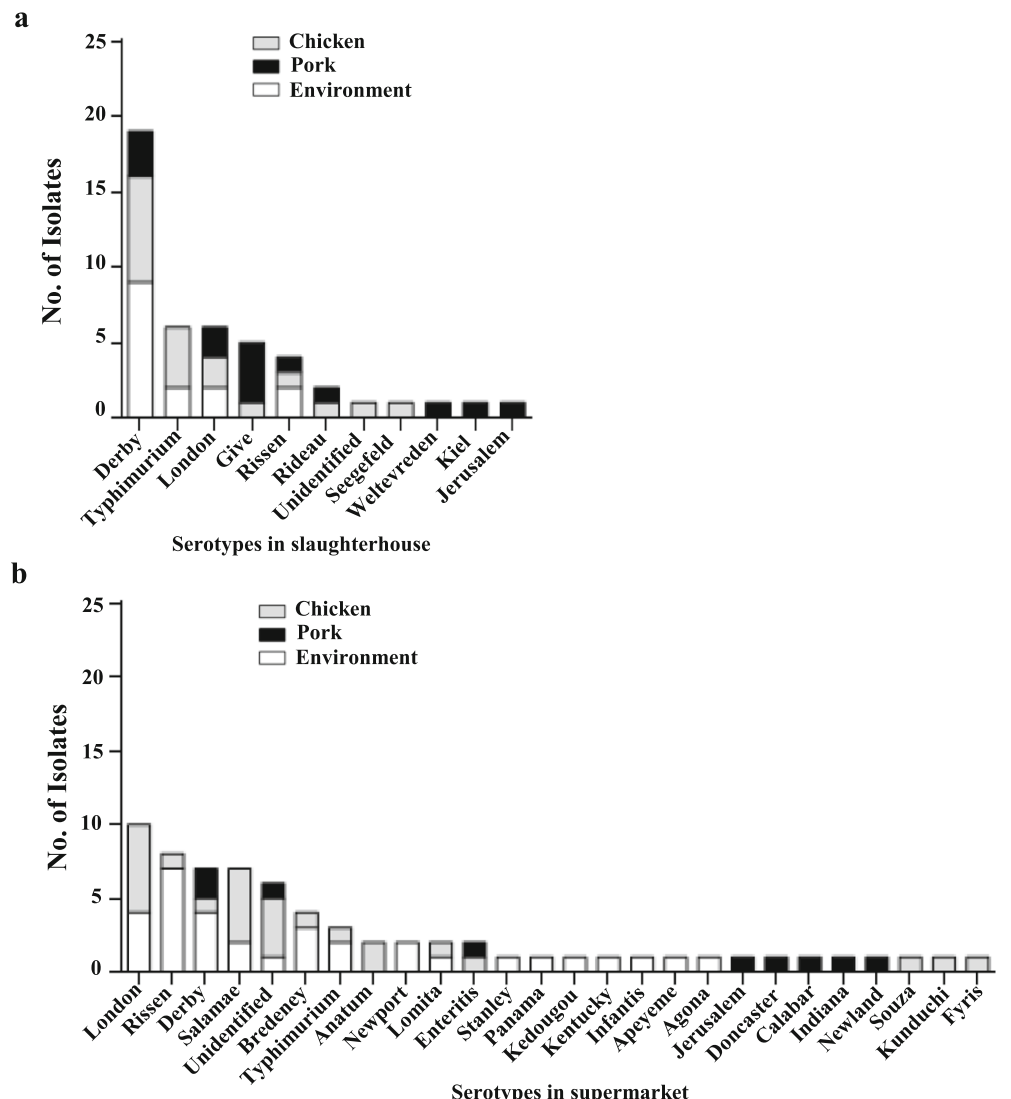

Fig. 1 Serotype results of Salmonella isolates. a Serotype results of isolates from chicken, pork and the environment in slaughterhouses. b Serotype results of isolates from chicken, pork and the environment in supermarkets

antibiotics in this study, especially that 16 out of 18 ST155 isolates were MDR strains (Fig. 3).

\section{Discussion}

For the purpose of this study, Salmonella isolates were recovered from scores of sites, including chicken, pork and the environment at abattoirs and supermarkets. Our results indicated that Salmonella was more frequently isolated in pork, and supermarkets exhibited a higher MDR Salmonella isolation rate and more diversity in serotypes and sequence types than slaughterhouses.

The overall isolation rate of Salmonella in our study was $10.25 \%$, which was lower than previous studies conducted in Sichuan province [11] and Yangzhou city [17], but close to surveys in three provinces of central China [21] and Germany [22]. It should be noted that although isolation rate at slaughterhouses (10.76\%) was similar to that at supermarkets (10.07\%), Salmonella appeared more frequently in pork $(44.00 \%)$ than that in chicken $(9.50 \%)$. Other studies also showed that Salmonella contamination rates in pork varies from 30 to $70 \%$ at retail markets [23, 24] and from 10 to $50 \%$ at slaughterhouses [25, 26], indicating that poor control measures were performed in slaughtering and retail chains of pork. For example, poor general hygiene and unsuitable storage conditions were commonly detected in pig slaughterhouses. Also, lacking of appropriate storage methods and regular disinfection increased the risk of Salmonella-colonizing activity at retail markets. In general, all of the differences attributed to collection seasons, amounts of samples and types, isolation methods and management.

$S$. Derby, generally detected in pork, could cause salmonellosis in many countries [27], and $S$. Rissen was generally considered to be transported through pig products in European countries [28]. In this study, $S$. Derby and $S$. Rissen were isolated from pork, chicken and the environment, and most of $S$. Derby isolates were detected in the environment. $S$. Derby was the dominant serotype, which was similar to other studies [11, 17]. $S$. Typhimurium and $S$. Enteritidis are the main serotypes causing acute human infection [29], and in this study 11 isolates were detected to be $S$. Enteritidis or $S$. Typhimurium, which had potential threats to public health. In addition, more categories of serotypes and sequence 

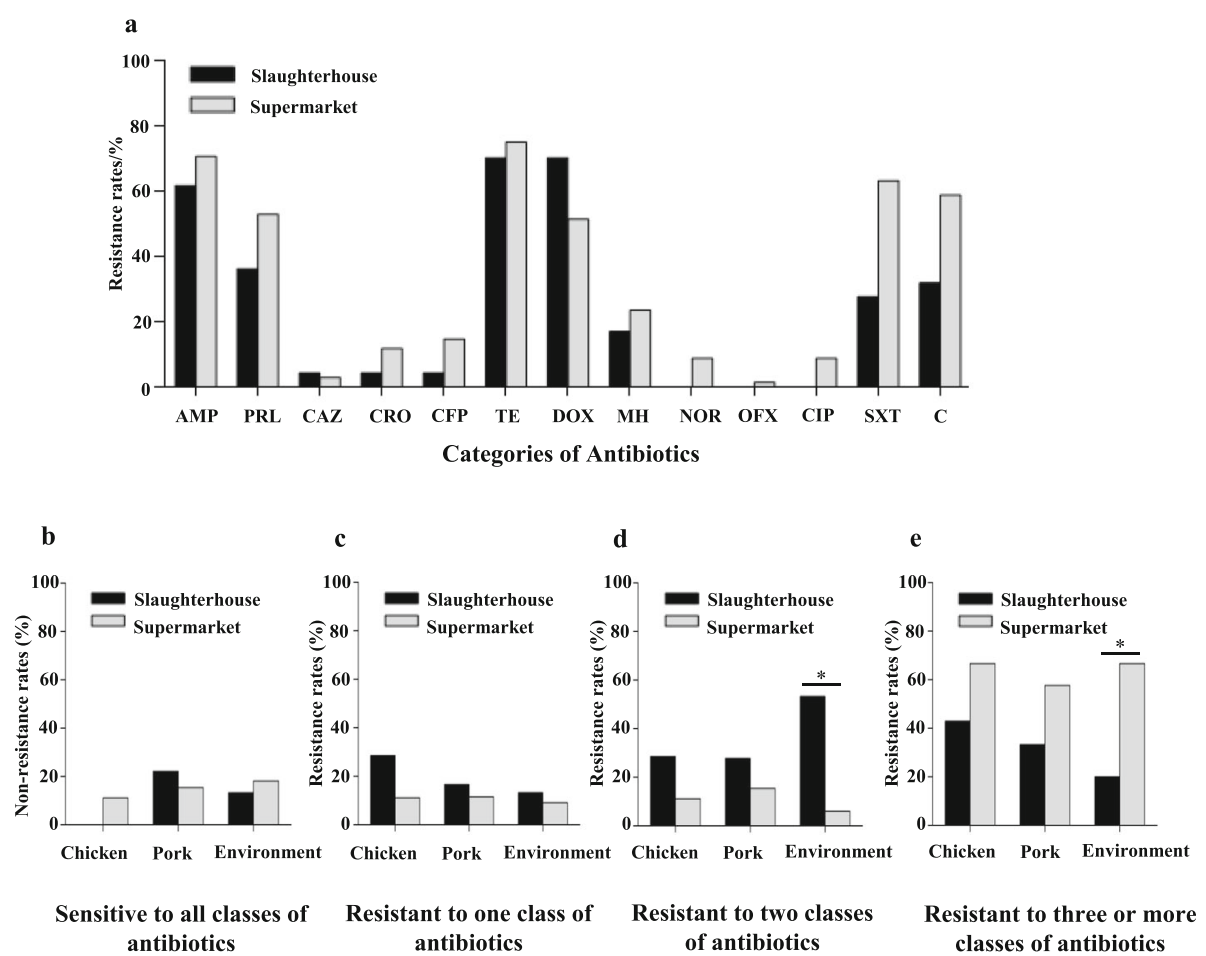

Fig. 2 Antimicrobial resistance results of Salmonella isolates. a The resistance rates of Salmonella from different sampling sources. $\mathbf{b}$ The rates of sensitivity Salmonella isolates to all classes of antibiotics. c The rates of resistant Salmonella isolates to one class antibiotics. $\mathbf{d}$ The rates of resistant Salmonella isolates to two classes antibiotics. e The rates of MDR Salmonella isolates. Statistical significance was determined by chi-squared test $\left({ }^{*} P<0.05\right)$

types were detected in isolates from supermarkets than that from slaughterhouses, demonstrating the various and abundant sources of contamination in retail process. Some STs in this study related to specific serovars, for instance $S$. London with ST155, ST469 with S. Rissen, and ST40 with $S$. Derby. Our results supported the conjecture that multilocus sequence typing could be an alternative method for serotyping in the future [30].

In this study, most of the isolates showed resistance to tetracycline and ampicillin, which was similar to a previous study [31]. The high resistance rate to these two antibiotics is reasonable, since these two antibiotics has been largely used in the husbandry industry in China [7]. It was noteworthy that more than half of the isolates exhibited MDR profiles, and compared with slaughterhouses, MDR Salmonella contamination occurred at supermarkets was much more frequently. The sanitation control strategies in supermarkets need to be carried out in this area to improve the safety of animal products.

\section{Conclusion}

In summary, the results of this study indicated that the contamination of Salmonella occurred in pork made it become a potential reservoir for human infection to some extent. In addition, although the isolation rate at supermarkets was close to that at slaughterhouses, isolates from supermarkets presented a high frequency of
MDR profiles and a wider range of serotypes and sequence types; these results indicated that Salmonella isolates from supermarkets were more threatening and their sources were much more complicated than that from slaughterhouses. Therefore, strict hygiene method and HACCP management in retail process should be taken into consideration to prevent foodborne infection caused by Salmonella.

\section{Methods}

\section{Sample collection}

Convenience sampling was carried out in 7 slaughterhouses and 5 supermarkets in 12 districts of Chongqing, China. From March to October in 2015, a total of 1112 samples were isolated. Chicken and pork were unpacked fresh meat; slaughtering environment including wash water $(n=30)$, knives $(\mathrm{n}=30)$, floor $(\mathrm{n}=30)$, feces $(n=15)$, apparatus $(\mathrm{n}=$ $30)$, containers $(n=30)$, tables $(n=30)$, carcasses $(n=30)$, and blood $(n=20)$; retail environment including chopping boards $(n=75)$, ice $(n=75)$, knives $(n=75)$, floor $(n=75)$, containers $(n=75)$, wash water $(n=75)$, and tables $(n=75)$. All collected samples were stored in an icebox and transported to a laboratory within $2 \mathrm{~h}$ of collection for immediate processing and then held in a refrigerator at $4{ }^{\circ} \mathrm{C}$.

\section{Isolation and serotyping}

After a pre-enrichment step of each sample in $10 \mathrm{~mL}$ sterile buffered peptone water (BPW) and incubated 


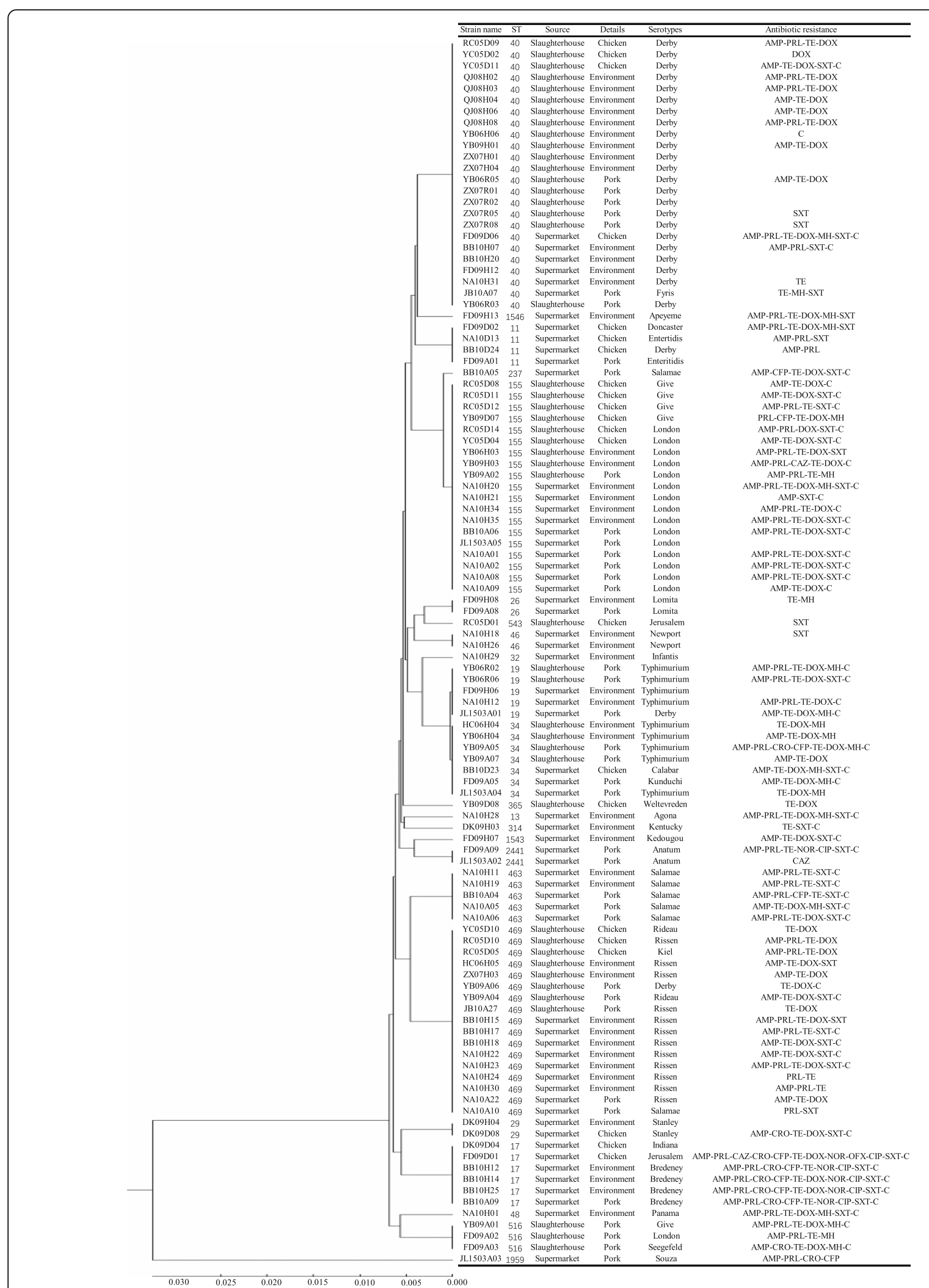

Fig. 3 Unweighted pair group method with arithmetic means (UPGMA) dendrogram based on multilocus sequence typing (MLST) profiles of the 108 Salmonella isolates from slaughterhouses and supermarkets 
overnight at $37^{\circ} \mathrm{C} .0 .2 \mathrm{~mL}$ of each pre-enriched suspensions were added into $2 \mathrm{ml}$ of Rappaport-Vassiliadis enrichment Broth (RVB) and $2 \mathrm{ml}$ of Tetrathionate broth (TTB) respectively, then incubated at $42{ }^{\circ} \mathrm{C}$ for $24 \mathrm{~h}$. One loopful of each RVB and TTB culture was then streaked onto Xylose Lysine Tergitol 4 (XLT-4) agar plates, which were incubated at $37^{\circ} \mathrm{C}$ for 24 to $48 \mathrm{~h}$. Among suspected colonies, only one was picked up from a plate and confirmed by specific gene through Polymerase Chain Reaction (PCR) of Salmonella using assays. Each isolate was serotyped by slide agglutination based on the Kauffmann-White-Le Minor Scheme [32].

\section{Antimicrobial susceptibility testing}

The standard Kirby-Bauer disk diffusion method recommended by the Clinical and Laboratory Standards Institute (CLSI, 2010) was carried out to test antimicrobial susceptibility of the Salmonella isolates to 13 categories of antimicrobials (Hangzhou Microbial Reagent., Ltd.): ampicillin (AMP $10 \mu \mathrm{g}$ ), cefoperazone (CFP $75 \mu \mathrm{g}$ ), piperacillin (PRL $100 \mu \mathrm{g}$ ), tetracycline (TE $30 \mu \mathrm{g})$, ceftazidime (CAZ $30 \mu \mathrm{g}$ ), doxycycline (DOX $30 \mu \mathrm{g}$ ), ceftriaxone (CRO $30 \mu \mathrm{g})$, minocycline (MH $30 \mu \mathrm{g})$, norfloxacin (NOR $10 \mu \mathrm{g}$ ), sulfamethoxazole (SXT $1.25 \mu \mathrm{g}$ ), ofloxacin (OFX $5 \mu \mathrm{g}$ ), chloramphenicol (C $30 \mu \mathrm{g}$ ) and ciprofloxacin (CIP $5 \mu \mathrm{g})$. Escherichia coli ATCC 25922 was invoked as the control organism. According to the CLSI, the isolates were considered to be susceptible, intermediate, or resistant. Salmonella isolates resistant to three or more antimicrobial classes were defined as MDR isolates.

\section{Multilocus sequence typing}

Protocols used for MLST of Salmonella were described online [33]. Seven housekeeping genes were amplified by PCR, including thrA, purE, sucA, hisD, aroC, hemD, and dnaN. PCR products were purified and sequenced by Sanger method, and the alleles and STs were assigned according to the MLST scheme [34]. The unweighted pair group method with arithmetic means analysis (UPGMA) was utilized to infer relationships among the isolates through MEGA7 software [35].

\section{Statistical analysis}

All statistical analyses were done using SPSS 20.0 (SPSS Inc., Chicago, IL), and the chi-squared test was applied to assess any statistically significant $(P<0.05)$ differences in this study.

\footnotetext{
Abbreviations

AMP: ampicillin; C: chloramphenicol; CAZ: ceftazidime; CFP: cefoperazone; CIP: ciprofloxacin; CLSI: Clinical and Laboratory Standards Institute; CRO: ceftriaxone; DOX: doxycycline; ESBL: Extended-spectrum- $\beta$-lactams; MDR: multidrug resistance; MH: minocycline; MLST: multilocus sequence typing; NOR: norfloxacin; OFX: ofloxacin; PRL: piperacillin; ST: sequence type; SXT: sulfamethoxazole; TE: tetracycline; UPGMA: the unweighted pair group method with arithmetic means analysis
}

\section{Acknowledgements}

Not applicable.

\section{Authors' contributions}

T.C., J.J., and D.X. performed the experiments and analyzed the data. Z.Z., J.X., and X.C. collected samples. C.Y., D.H., and Y.P. helped in analyzing the data and designing the experiments. R.F., supervised the study, R.F., T.C., and J.J., drafted the manuscript. All authors read and approved the final manuscript

\section{Funding}

This work was supported by the National Key Research and Development Program of China (2018YFD0500500), the Chongqing Science \& Technology Commission (cstc2018jscx-msybX0302), the Fundamental Research Funds for the Central Universities (XDJK2019B012), the National Agricultural Product Quality and Safety Risk Assessment Project (GJFP2019007), the Earmarked Fund for China Agriculture Research System (CARS-37), the Beibei Science \& Technology Commission (No. 2018-20). The funding bodies had no role in study design, data collection or analysis, decision to publish or preparation.

\section{Availability of data and materials}

The datasets used and/or analyzed during the current study available from the corresponding author on reasonable request.

Ethics approval and consent to participate

Samples from slaughterhouses and supermarkets were sampled with the verbal consent of the slaughterhouse and supermarket owners. All animal procedures were reviewed and approved by Institutional Animal Care and Use Committee of Southwest University (Permit No. IACUC-2015-0219-03).

\section{Consent for publication}

Not applicable.

\section{Competing interests}

The authors declare that they have no competing interests.

\section{Author details}

${ }^{1}$ College of Animal Science and Technology, Southwest University, No. 2 Tiansheng Road, Beibei District, Chongqing 400715, China. ${ }^{2}$ Chongqing Animal Disease Prevention and Control Center; Laboratory of Quality \& Safety Risk Assessment for Animal Products on Biohazards, Ministry of Agriculture, Chongqing 401120, China. ${ }^{3}$ Animal Husbandry and Aquatic Products Station of Yubei District, Chongqing 401120, China. ${ }^{4}$ Department of Zoonoses, Kitasato University School of Veterinary Medicine, Towada 034-8628, Japan.

Received: 7 August 2019 Accepted: 28 November 2019 Published online: 18 December 2019

\section{References}

1. Newell DG, Koopmans M, Verhoef L, Duizer E, Aidara-Kane A, Sprong H, Opsteegh M, Langelaar M, Threfall J, Scheutz F, et al. Food-borne diseases the challenges of 20 years ago still persist while new ones continue to emerge. Int J Food Microbiol. 2010;139(Suppl 1):S3-15.

2. Abraham S, Groves MD, Trott DJ, Chapman TA, Turner B, Hornitzky M, Jordan D. Salmonella enterica isolated from infections in Australian livestock remain susceptible to critical antimicrobials. Int J Antimicrob Ag. 2014;43(2): $126-30$.

3. Mikanatha NM, Sandt CH, Localio AR, Tewari D, Rankin SC, Whichard JM, Altekruse SF, Lautenbach E, Folster JP, Russo A, et al. Multidrug-resistant Salmonella isolates from retail chicken meat compared with human clinical isolates. Foodborne Pathog Dis. 2010;7(8):929-34.

4. Campos J, Mourao J, Peixe L, Antunes P. Non-typhoidal Salmonella in the pig production chain: a comprehensive analysis of its impact on human health. Pathogens. 2019;8:1.

5. Sarmah AK, Meyer MT, Boxall AB. A global perspective on the use, sales, exposure pathways, occurrence, fate and effects of veterinary antibiotics (VAs) in the environment. Chemosphere. 2006;65(5):725-59.

6. Zhou LJ, Ying GG, Liu S, Zhang RQ, Lai HJ, Chen ZF, Pan CG. Excretion masses and environmental occurrence of antibiotics in typical swine and dairy cattle farms in China. Sci Total Environ. 2013;444:183-95. 
7. Zhang QQ, Ying GG, Pan CG, Liu YS, Zhao JL. Comprehensive evaluation of antibiotics emission and fate in the river basins of China: source analysis, multimedia modeling, and linkage to bacterial resistance. Environ Sci Technol. 2015:49(11):6772-82.

8. Harrois D, Breurec S, Seck A, Delaune A, Le Hello S, Pardos de la Gandara M, Sontag L, Perrier-Gros-Claude JD, Sire JM, Garin B, et al. Prevalence and characterization of extended-spectrum beta-lactamase-producing clinical Salmonella enterica isolates in Dakar, Senegal, from 1999 to 2009. Clin Microbiol Infect. 2014:20(2):109-16.

9. Liu WB, Liu B, Zhu XN, Yu SJ, Shi XM. Diversity of Salmonella isolates using serotyping and multilocus sequence typing. Food Microbiol. 2011;28(6): 1182-9.

10. Lindstedt BA, Heir E, Vardund T, Kapperud G. A variation of the amplifiedfragment length polymorphism (AFLP) technique using three restriction endonucleases, and assessment of the enzyme combination Bglll-Mfel for AFLP analysis of Salmonella enterica subsp. enterica isolates. FEMS Microbiol Lett. 2000;189(1):19-24

11. Ma S, Lei C, Kong L, Jiang W, Liu B, Men S, Yang Y, Cheng G, Chen Y, Wang $\mathrm{H}$. Prevalence, antimicrobial resistance, and relatedness of Salmonella isolated from chickens and pigs on farms, abattoirs, and markets in Sichuan province, China. Foodborne Pathog Dis. 2017;14:11.

12. Murase T, Nakamura A, Matsushima A, Yamai S. An epidemiological study of Salmonella enteritidis by pulsed-field gel electrophoresis (PFGE): several PFGE patterns observed in isolates from a food poisoning outbreak. Microbiol Immunol. 2013;40(11):873-5.

13. McDermott PF, Tyson GH, Kabera C, Chen Y, Li C, Folster JP, Ayers SL, Lam C, Tate HP, Zhao S. Whole-genome sequencing for detecting antimicrobial resistance in nontyphoidal Salmonella. Antimicrob Agents Chemother. 2016; 60(9):5515-20

14. Nabil-Fareed A, Zhemin Z, Sergeant MJ, Achtman M, Casadesús J. A genomic overview of the population structure of Salmonella. Plos Genet. 2018;14(4):e1007261.

15. Hur J, Jawale C, Lee JH. Antimicrobial resistance of Salmonella isolated from food animals: a review. Food Res Int. 2012:45(2):819-30.

16. Li R, Lai J, Wang Y, Liu S, Li Y, Liu K, Shen J, Wu C. Prevalence and characterization of Salmonella species isolated from pigs, ducks and chickens in Sichuan Province, China. Int J Food Microbiol. 2013;163(1):14-8.

17. Cai $Y$, Tao J, Jiao $Y$, Fei $X$, Zhou L, Wang $Y$, Zheng H, Pan Z, Jiao X. Phenotypic characteristics and genotypic correlation between Salmonella isolates from a slaughterhouse and retail markets in Yangzhou, China. Int J Food Microbiol. 2016:222:56-64.

18. Zhang $W H$, Lin XY, Xu L, Gu XX, Yang L, Li W, Ren SQ, Liu YH, Zeng ZL, Jiang HX. CTX-M-27 producing Salmonella enterica serotypes Typhimurium and Indiana are prevalent among food-producing animals in China. Front Microbiol. 2016;7:436.

19. Ed-dra A, Filali FR, Karraouan B, El Allaoui A, Aboulkacem A, Bouchrif B. Prevalence, molecular and antimicrobial resistance of Salmonella isolated from sausages in Meknes, Morocco. Microb Pathog. 2017;105:340-5.

20. Casanova-Higes A, Andres-Barranco S, Mainar-Jaime RC. Influence of onfarm pig Salmonella status on Salmonella shedding at slaughter. Zoonoses Public Health. 2017;64(5):328-36.

21. Kuang X, Haihong H, Menghong D, Yulian W, ljaz A, Zhenli L, Yuan Z. Serotypes and antimicrobial susceptibility of Salmonella spp isolated from farm animals in China. Front Microbiol. 2015;6:602.

22. Visscher CF, Klein G, Verspohl J, Beyerbach M, Stratmann-Selke J, Kamphues J. Serodiversity and serological as well as cultural distribution of Salmonella on farms and in abattoirs in Lower Saxony, Germany. Int J Food Microbiol. 2011;146(1):44-51.

23. Zhang L, Fu Y, Xiong Z, Ma Y, Wei Y, Qu X, Zhang H, Zhang J, Liao M. Highly prevalent multidrug-resistant Salmonella from chicken and pork meat at retail markets in Guangdong, China. Front Microbiol. 2018;9:2104.

24. Miao Z, Li S, Qin K, Zhou Y. Prevalence and antimicrobial resistance of Salmonella isolates recovered from retail pork in major village markets in Tai'an region, China. J Food Prot. 2017;80(10):1635-40.

25. Fois F, Piras F, Torpdahl M, Mazza R, Consolati SG, Spanu C, Scarano C, De Santis EPL. Occurrence, characterization, and antimicrobial susceptibility of Salmonella enterica in slaughtered pigs in Sardinia. J Food Sci. 2017;82(4): 969-76.

26. Carraturo F, Gargiulo G, Giorgio A, Aliberti F, Guida M. Prevalence, distribution, and diversity of Salmonella spp. in meat samples collected from Italian slaughterhouses. J Food Sci. 2016;81(10):M2545-51.
27. None. Report of the task force on zoonoses data collection on the analysis of the baseline survey on the prevalence of Salmonella in broiler flocks of Gallus gallus, in the EU, 2005-2006 - Part B: factors related to Salmonella flock prevalence, distribute. EFSA J. 2007;5(10):101.

28. Hendriksen RS, Bangtrakulnonth A, Pulsrikarn C, Pornreongwong S, Hasman $\mathrm{H}$, Song SW, Aarestrup FM. Antimicrobial resistance and molecular epidemiology of Salmonella Rissen from animals, food products, and patients in Thailand and Denmark. Foodborne Pathog Dis. 2008:5(5):605-19.

29. Hendriksen RS, Vieira AR, Karlsmose S, Lo Fo Wong DMA, Jensen AB, Wegener HC, Aarestrup FM. Global monitoring of Salmonella serovar distribution from the world health organization global foodborne infections network country data Bank: results of quality assured laboratories from 2001 to 2007. Foodborne Pathog Dis. 2011;8(8):887.

30. Achtman M, Wain J, Weill FX, Nair S, Zhou Z, Sangal V, Krauland MG, Hale $J$, Harbottle $H$, Uesbeck A, et al. Multilocus sequence typing as a replacement for serotyping in Salmonella enterica. PLoS Pathog. 2012;8(6): e1002776.

31. Zhao X, Chaoqun Y, Weishan C, Shuhong S. Serotype distribution, antimicrobial resistance, and class 1 integrons profiles of Salmonella from animals in slaughterhouses in Shandong province, China. Front microbiol. 2017:8:1049

32. Issenhuth-Jeanjean $\mathrm{S}$, Roggentin $\mathrm{P}$, Mikoleit M, Guibourdenche $\mathrm{M}$, de Pinna E, Nair S, Fields PI, Weill FX. Supplement 2008-2010 (no. 48) to the WhiteKauffmann-Le Minor scheme. Res Microbiol. 2014;165(7):526-30.

33. Protocols used for MLST of Salmonella enterica. https://enterobase. readthedocs.io/en/latest/mlst/mlst-legacy-info-senterica.html. Accessed 2 August 2019.

34. EnteroBase. http://enterobase.warwick.ac.uk/species/index/senterica. Accessed 2 August 2019

35. Kumar S, Stecher G, Tamura K. MEGA7: molecular evolutionary genetics analysis version 7.0 for bigger datasets. Mol Biol Evol. 2016;33(7):1870.

\section{Publisher's Note}

Springer Nature remains neutral with regard to jurisdictional claims in published maps and institutional affiliations.

\section{Ready to submit your research? Choose BMC and benefit from:}

- fast, convenient online submission

- thorough peer review by experienced researchers in your field

- rapid publication on acceptance

- support for research data, including large and complex data types

- gold Open Access which fosters wider collaboration and increased citations

- maximum visibility for your research: over $100 \mathrm{M}$ website views per year

At BMC, research is always in progress.

Learn more biomedcentral.com/submission 